\title{
Fabrication of silicone tubes in experimental nerve surgery
}

\author{
MM Al-Qattan MB BS FRCSC \\ Division of Plastic Surgery, King Saud University, Riyadh, Saudi Arabia
}

\begin{abstract}
MM Al-Qattan. Fabrication of silicone tubes in experimental nerve surgery. Can J Plast Surg 1995;3(1):54-55. A technique of fabricating silicone tubes to the desired dimensions from a silicone sheet is described. The fabricated tube was used successfully as a conduit for the rat tibial nerve defect. The advantages and disadvantages of fabricated tubes are discussed.
\end{abstract}

Key Words: Experimental surgery, Nerve conduit, Nerve surgery, Silicone tube

\section{Fabrication de tubes de silicone dans une chirurgie expérimentale des nerfs}

RÉSUMÉ : Une technique de fabrication de tubes de silicone de dimensions souhaitées à partir d'une feuille de silicone est décrite ici. Le tube fabriqué a été utilisé avec succès comme conduit pour un défaut du nerf tibial chez le rat. Les avantages et inconvénients des tubes fabriqués sont discutés.

$\mathrm{T}$ here has been a recent interest in 'biological' treatment of nerve injuries using silicone tubes. The proximal and distal nerve stumps are enclosed in a silicone tube leaving a short gap between the two stumps. This technique has been used both experimentally (1) and in humans (2). Silicone tubes have also been used to 'band' intact nerves experimentally to produce chronic nerve compression (3). This paper describes a technique of fabricating silicone tubes to the desired dimensions from a silicone sheet.

\section{MATERIALS AND METHODS}

A silicone sheet $(0.005$ inch thick, non-reinforced medical grade silicone rubber, Dow Corning, Midland, Michigan) that is commonly used as a subdermal implant is used to fabricate silicone tubes of different dimensions. The fabrication of a $10 \mathrm{~mm}$ silicone conduit with an inner diameter of $1.5 \mathrm{~mm}$ will be described here because such a conduit is suitable for the rat tibial nerve defect. However, the same technique can be used to fabricate larger or even smaller tubes.

The procedure was done using an operating microscope and a piece of silicone sheet measuring $5 \times 10 \mathrm{~mm}$. The tube was fabricated by suturing the two long borders together using multiple interrupted 10-0 nylon sutures. The resulting

Correspondence and reprints: Dr MM Al-Qattan, PO Box 18097, Riyadh 11415, Saudi Arabia. Telephone 011-9661-464-3395, Fax 011-9661-467-9493 tube was $10 \mathrm{~mm}$ long with an inner diameter of $1.5 \mathrm{~mm}$ (Figure 1). The tube was then used to bridge a $6 \mathrm{~mm}$ gap of the rat tibial nerve by inserting $2 \mathrm{~mm}$ of the proximal and distal stumps into both ends of the tube. The nerve ends were fixed to the tube with two epineurial sutures (10-0 nylon).

\section{RESULTS}

Fabrication of each silicone tube took about 15 mins. The fabricated tubes did not collapse and successful nerve regeneration across the nerve gap was obtained.

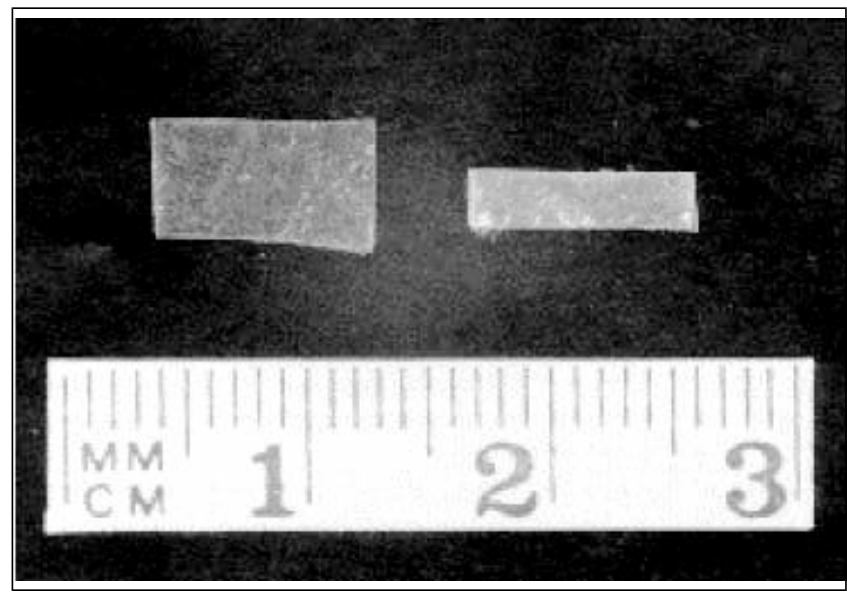

Figure 1) Silastic sheet (left) measuring $5 \times 10 \mathrm{~mm}$ is used to fabricate a silicone tube (right) by suturing the two long borders of the sheet with interrupted 10-0 nylon sutures 


\section{DISCUSSION}

When compared with manufactured 'readymade' silicone tubes, self-fabricated tubes have two main advantages: lower cost (a single silicone sheet of $30 \times 15 \mathrm{~cm}$ can be used to fabricate 30 tubes); and fabrication to the desired dimensions is possible without having to order tubes of different sizes. Furthermore, the tube can be fabricated in situ to 'band' intact nerves experimentally to produce chronic nerve compression. When 'readymade' tubes were used to 'band' intact rat sciatic nerves (3), the tube had to be split longitudinally, then slipped around the intact nerve and nylon sutures were then placed into the silastic to close the tube (3).

Disadvantages of self-fabricated tubes include the time taken for fabrication and the need for a 10-0 nylon suture. In order not to waste any time while the animal is anaesthetized, the tubes can be fabricated before anaesthesia. The same 10-0 nylon suture used to fabricate the tube can also be used to suture the nerve ends to the silicone.

\section{REFERENCES}

1. Zeng L, Worseg A, Albrecht G, et al. A non invasive functional evaluation following peripheral nerve repair with electromyography in a rat model. Plast Reconstr Surg 1994;94:146-51.

2. Lundborg G, Rosen B, Abrahmason SO, Dahlin L, Danielsen N. Tubular repair of the median nerve in the human forearm. Preliminary findings. J Hand Surg 1994,19B:273-6.

3. Dellon AL, Mackinnon SE, Seiler IV WA. Susceptibility of the diabetic nerve to chronic compression. Ann Plast Surg 1988;20:117-9. 